\title{
GREG WiNTER Y LA EvOLUCIÓN DiRIGIDA
}

\author{
Greg Winter and Directed Evolution
}

Jorge Arévalo Zelada ${ }^{1}$

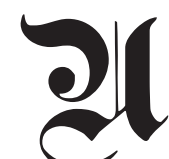
n niño británico, a inicios de los 1960s en una escuela de Costa de Oro, lo que hoy en día es Ghana, miraba con gran asombro y tremendo entusiasmo a una enorme tortuga marina viva que un científico llevó a la escuela. Es ese recuerdo al que Greg Winter atribuye el inicio de su posterior dedicación a la ciencia. En la entrevista donde refiere ese hecho Greg añade: "qué vida tan excitante debe ser la de ir alrededor del mundo capturando animales y luego ser capaz de presentarse ante otros y decir a la gente qué cosa hacer. Ese hecho me dejó enganchado. Gradualmente descubrí que la frontera de lo desconocido no estaba en el sentido de ser una suerte de David Attenborough que sale y explora el mundo natural. Fue bastante claro que con las moléculas habia fronteras asi de nuevas y excitantes".

Transcurridos muchos años desde aquella escena, en aquel país fuera del circuito de la ciencia de avanzada, el 3 de octubre de 2018 la Real Academia de Ciencias de Suecia anunció que otorgaba el Premio Nobel de Química a Frances H. Arnold (EE.UU.) por la evolución dirigida de enzimas y de manera conjunta a George P. Smith (EE.UU.) y Sir Gregory P. Winter (Reino Unido) por el phage display de

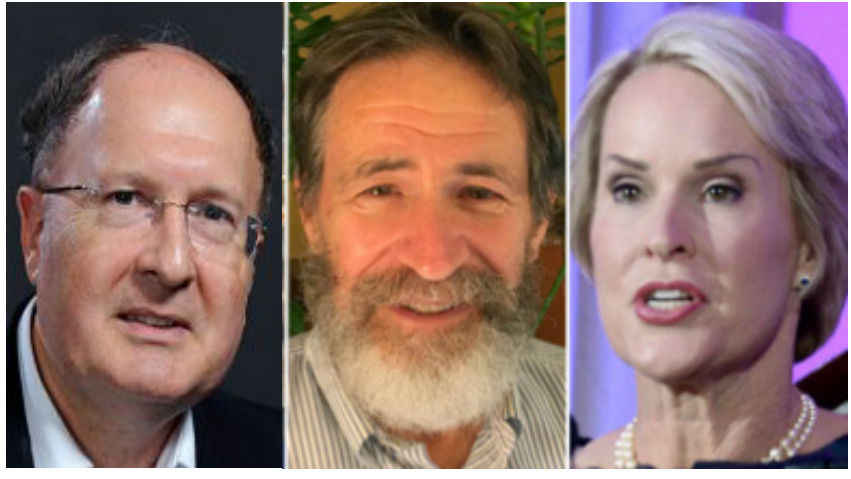

Gregory P. Winter, George P. Smith y Frances H. Arnold

péptidos y anticuerpos. Los tres investigadores realizaron contribuciones independientes no sólo para la obtención de proteínas que no existen de manera espontánea en la naturaleza sino que mediante tecnologías innovadoras sus moléculas artificiales estaban provistas de nuevas funciones. En otras palabras, crearon nuevas funciones a través del conocimiento íntimo de la estructura y función de las macromoléculas informacionales.

Había transcurrido un largo camino desde que los padres de Greg Winter llegaron a Costa de Oro desde Leicester (RU) en septiembre de 1951 para proteger la salud frágil de Greg,

1 Profesor Principal del Departamento de Bioquímica, Biología Molecular y Farmacología. Universidad Peruana Cayetano Heredia. 
un niño de cinco meses de edad y que nació prematuro de seis semanas, en una época donde esa condición era de alto riesgo y más aún por el racionamiento de la calefacción en los fríos inviernos en la Europa de la postguerra. Era notable el valor de esa decisión de los Winter de migrar al clima cálido de Costa de Oro en una época de gran inestabilidad social en aquella ex colonia británica que vivía su periodo más incierto y que culminó en 1961 con su independencia del Reino Unido. Bajo esas condiciones adversas, el joven Greg Winter fue expuesto a una gran diversidad étnica, de personas con distintos credos, religiones y profesiones.

A la edad de los 15 años retornó al Reino Unido culminando sus estudios de pregrado en el Trinity College de Cambridge y tres años después recibió el grado de PhD, en 1976, en el Laboratorio de Biología Molecular del MRC en la Universidad de Cambridge. Sus primeros trabajos fueron sobre la generación de mutaciones en dominios funcionales de proteínas virales para modificar las propiedades de las enzimas que estudiaba. Fue a inicios de los 1980's en el MRC de Cambridge que, bajo la influencia de César Milstein, Greg Winter reorientó su investigación para modificar dominios de las proteínas y aplicarla al estudio y el uso de la diversidad de los anticuerpos. En aquel entonces un problema crítico de los anticuerpos monoclonales inventados por César Milstein y Georges Köhler fue el que habiéndose usado el modelo animal de ratón para obtener los anticuerpos monoclonales a partir de la respuesta inmune humoral, esas moléculas tenían regiones propias de la especie murina y distintas de las del Homo sapiens. Este hecho impedía el uso terapéutico de los anticuerpos monoclonales ya que los dominios propios del ratón generarían una respuesta inmune neutralizante, anulando así la capacidad terapeútica del anticuerpo monoclonal. La pregunta conceptual que se hizo Greg Winter fue si las CDRs (Complementarity Determining Regions), que eran las regiones variables del anticuerpo que se asumían eran las que reconocían los epítopes, eran funcionalmente independientes de las FR (Framework Regions) que flanqueaban a los CDRs. Obviamente, esos límites entre ambas secuencias del polipéptido no eran evidentes desde el punto de vista estructural. Mediante experimentos elegantes empleando sintesis química de oligonucleótidos, manipulación de fragmentos de ADN y expresión de proteínas en E. coli, Greg Winter y su equipo injertaron los CDR de un anticuerpo monoclonal originado en ratón en el armazón de una molécula de anticuerpo de origen humano. Al final del proceso el anticuerpo monoclonal "humanizado" tenía secuencias FR humanas flanqueando los CDR de ratón. Más interesante aun la afinidad por el hapteno diana, 4-hydroxy-3-nitrophenacetyl caproic acid, era muy semejante a la presentada por el anticuerpo monoclonal de ratón. Se comprobó así que el fragmento injertado contenía los atributos de unión a la molécula ligando. En otras palabras, la mayor parte de la estructura del anticuerpo es una armazón en el cual solo una porción de ella contiene la función de afinidad por su antígeno. Cambiando esa región en el armazón se adquiere una molécula con una nueva afinidad.

El siguiente gran paso de Greg Winter fue el independizarse del modelo de mamífero para la producción de anticuerpos. Para ello utilizó el sistema de phage display inventado por George P. Smith, el otro galardonado con el Nobel. Una librería combinatoria aleatoria de fagos filamentosos, fd, que expresaban sobre su cápside la región variable de anticuerpos de tipo humano. Cada fago expresaba sobre su superficie un anticuerpo monoclonal pero diferente de los expresados en los otros fagos 
de esa población. Mediante el tamizaje con una molécula hapteno blanco fueron capaces de seleccionar anticuerpos monoclonales específicos. Por primera vez se imitaba un proceso de selección clonal independiente del sistema inmune de mamíferos. Con ellos se obtenía anticuerpos casi 100\% humanizados. Michael Neuberger, notable investigador con extraordinarias contribuciones al entendimiento de la generación de los tipos de anticuerpos y a la hipermutación somática responsable de la maduración de los anticuerpos, recuerda la excitación intensa de Greg Winter sobre las posibilidades prácticas de esta manipulación para alterar la estructura de los anticuerpos. Michael nos dice: "En un entorno que probablemente se prestaba más a la investigación básica pura, [Greg] fue muy rápido para ver cómo llevar las cosas a la comercialización, así como a la clínica."

En 1989 Greg Winter y David Chiswell fundaron CAT (Cambridge Antibody Technology) dado que la posibilidad de conseguir dinero público para desarrollar drogas en base a anticuerpos escapaba a toda posibilidad y existía una presión de competencia con los EE.UU. Tampoco era fácil captar inversiones privadas para un periodo donde la propuesta de anticuerpos monoclonales como drogas era considerada una herejía científica. Las drogas eran concebidas necesariamente como compuestos químicos de bajo peso molecular. La apuesta de Greg Winter y su socio produjeron el primer anticuerpo humanizado denominado adalimumab (Humira ${ }^{\circledR}$ ), el que fue aprobado el 2002 para el tratamiento de artritis reumatoidea y posteriormente para psoriasis y enfermedades inflamatorias del intestino. En el año 2017 fue la droga más vendida, generando ingresos por 18400 millones de dólares. Posteriormente, el año 2000 fundó Domantis que utilizó solo el dominio funcional de los anticuerpos 100\% humanizados. Hoy en día, anticuerpos monoclonales como trastuzumab (Herceptin $\AA$ ) $u$ otras de naturaleza de anticuerpos son basadas en la tecnología desarrollada por Greg Winter. En el año 2009 fundó otra empresa, Bicycle Therapeutics, para una nueva clase de fármacos que funcionan como mini-anticuerpos. En el año 2006, CAT fue comprada por Astra Zeneca for $£ 700$ millones y Domantis fue adquirida por GlaxoSmithKline por $£ 230$ millones. El MRC de la Universidad de Cambridge recibió alrededor de $£ 390$ millones de ingresos por la propiedad intelectual de Greg Winter. No es extraño que esa y otras contribuciones de Greg Winter al mundo de la industria de los anticuerpos lo hayan colocado entre los cinco personajes más influyentes de la misma.

Greg Winter posee una percepción muy clara del entorno donde se desarrolla la investigación científica. Es un crítico de la dicotomía entre ciencia básica y aplicada y resalta la importancia de la inversión pública en la investigación que lleva a descubrimientos aún sin tener la certidumbre de que ella nos llevará a aplicaciones útiles. En una entrevista que Greg Winter otorgó a Nature Biotechnology, él mencionó que se consideraba una persona con suerte porque el Laboratorio de Biología Molecular en Cambridge le dio "carta blanca" para continuar con su trabajo, sin hacer distinciones entre investigación básica y aplicada. "Hubiera sido muy difícil hacer mis invenciones bajo las formas convencionales de financiamiento (hubiera sido considerada como muy aplicada) o con dinero de la industria (hubiera sido vista como demasiado temprana, y de cualquier forma la mayoría de las compañías no estaban interesadas en los anticuerpos al principio." Sobre el rol del Estado y la importancia del recurso humano es bastante claro cuando afirma:» Si el gobierno no lo hace nadie más financiará 
la ciencia del descubrimiento. Nadie más te dará dinero para hacer un trabajo que podría generar beneficios en 20 o 70 años. Nosotros necesitamos mantener un cuadro de científicos en el Reino Unido financiado por el Gobierno para trabajar tanto en investigación básica como en investigación aplicada»

Esta breve reseña biográfica nos deja temas de conversación y debate. Es muy importante la inteligencia y perseverancia del acto de investigar pero se requiere de un entorno intelectual y material que propicie la investigación con calidad y ambición. La universidad es un ámbito donde la creatividad puede prosperar pero se requiere recurso humano e infraestructura, y mucha paciencia para cosechar los frutos.

El modelo universitario predominante hoy en día en el Perú es un contrasentido a las experiencias exitosas de las universidades reconocidas por su producción de conocimiento. También nos dice que esa investigación puede ser responsable de la sostenibilidad cuando esté en una sociedad que concibe la ciencia como una fuente de riqueza. Es un rol de la universidad el influenciar sobre los que conducen los destinos del país.

\section{CORRESPONDENCIA:}

jorge.arevalo@upch.pe 